\title{
The case for dynamic subsidence of the U.S. east coast since the Eocene
}

\author{
Sonja Spasojević, ${ }^{1}$ Lijun Liu, ${ }^{1}$ Michael Gurnis, ${ }^{1}$ and R. Dietmar Müller ${ }^{2}$ \\ Received 4 February 2008; revised 16 March 2008; accepted 19 March 2008; published 22 April 2008.
}

[1] The dynamic subsidence of the United States east coast is addressed using the discrepancy between regional and global estimates of sea level, elevation of paleoshorelines, and adjoint models of mantle convection that assimilate plate motions and seismic tomography. The positions of Eocene and Miocene paleoshorelines are lower than predicted by global sea levels, suggesting at least $50 \mathrm{~m}$, and possibly as much as $200 \mathrm{~m}$ of subsidence since the end of the Eocene. Dynamic models predict subsidence of the east coast since the end of Eocene, although the exact magnitude is uncertain. This subsidence has been occurring during an overall global sea-level fall, with the eustatic change being larger than the dynamic subsidence; this results in a regional sea-level fall in the absence of land subsidence. Dynamic subsidence is consistent with the difference between eustasy and regional sea level at the New Jersey coastal plain. Citation: Spasojević, S., L. Liu, M. Gurnis, and R. D. Müller (2008), The case for dynamic subsidence of the U.S. east coast since the Eocene, Geophys. Res. Lett., 35, L08305, doi:10.1029/2008GL033511.

\section{Introduction}

[2] The mantle density structure drives a large-scale pattern of surface dynamic topography that may play an important role in controlling the geoid [Richards and Hager, 1984; Hager et al., 1985]. North America has been suggested as a dynamic topography low using density structures either inferred from seismic tomography [Hager et al., 1985; Steinberger, 2007] or the history of subduction [Lithgow-Bertelloni and Richards, 1998]. Both global [Grand, 2002; Ritsema and van Heijst, 2000] and regional [Ren et al., 2007] seismic tomography models show a linear high seismic velocity anomaly beneath eastern North America at mid mantle depths, interpreted as the remnants of Farallon plate subduction [Bunge and Grand, 2000; Ren et al., 2007].

[3] Independent of these geophysical concepts, Miller et al. [2005] made new sea-level estimates that putatively reflect eustasy, based on the backstripping of sedimentary sections at five boreholes located on the New Jersey coastal plain [Van Sickel et al., 2004]. The maximum long-term sea level is around $70 \mathrm{~m}$ [Miller et al., 2005], which is lower than most other published global sea-level estimates (Figure 1a). The high-end estimates of sea level with a maximum on order of $250-300 \mathrm{~m}$ (Figure 1a) are based on correlations of stratigraphic sequences in wells, outcrops

\footnotetext{
${ }^{1}$ Seismological Laboratory, California Institute of Technology, Pasadena, California, USA.

${ }^{2}$ School of Geosciences, University of Sydney, Sydney, New South Wales, Australia.
}

Copyright 2008 by the American Geophysical Union. 0094-8276/08/2008GL033511\$05.00 and seismic data [Haq et al., 1987; Haq and Al-Qahtani, 2005], with the long-term trend linked to the estimates from changing mid-ocean ridge volume [e.g., Kominz, 1984]. Low-end estimates with maximum of $120 \mathrm{~m}$ are based on backstripping of wells on the continental margin of eastern North America [Watts and Steckler, 1979]. Müller et al. [2008] assimilated marine geophysical data into reconstruction of ancient ocean basins, modeling a Late Cretaceous maximum of $170 \mathrm{~m}$ (Figure 1a). Kominz [1984] estimated global sea-level variations due to changing mid ocean ridge volume (Figures 1a and 1b), which closely matched the component of sea level required to flood continental interiors (Figure 1b), especially since the Eocene, as determined through hypsometric analysis [Harrison, 1990; Bond, 1979]. In addition, by compensating for regional variations in flooding with respect to average trends, Bond [1979] determined long wavelength vertical epeirogenic motions that are consistent with geodynamic models [e.g., LithgowBertelloni and Gurnis, 1997].

[4] Although all global sea-level estimates are subject to considerable uncertainty [Miller et al., 2005], the flooding of continental interiors seems most reasonable to us. First, the method averages over large length scales within relatively stable continental interiors, hence avoiding the need to subtract the much larger change due to thermal subsidence of rifted margins. Second, geodynamic models suggest that most locations are subject to long-term vertical motions [e.g., Gurnis, 1992; Lithgow-Bertelloni and Gurnis, 1997] and hence methods that depend on a few boreholes in close proximity could be subject to regional effects, as we will describe below. Finally, it has been argued that methods that depend on global correlation of stratigraphic sequences only extract higher frequency sea-level change, and longterm sea-level fluctuations must be obtained by calibration with flooding of continental interiors.

[5] If we compare the Miller et al. [2005] long-term sealevel estimate with other estimates, especially those consistent with the flooding of continental interiors, there appears to be a significant discrepancy between maximum Late Cretaceous sea levels on the order of 50-200 meters (Figure 1). Consequently, we hypothesize that the estimate of Miller et al. [2005] reflects regional, rather than global sea-level variations on the $10^{7}$ year scale considered here. Further, we suggest that the discrepancy is driven by a dynamic subsidence of the eastern areas of the United States but the magnitude of the subsidence has been somewhat smaller than the fall in global sea level over the same period. We approach this hypothesis from two directions, one empirical, and the other involving mantle flow models. First, we reconstruct paleoshorelines in eastern United States and use them to estimate subsidence that is independent of the New Jersey boreholes. Second, we use adjoint models of mantle convection from L. Liu et al. (Reconstruction of Farallon Plate subduction beneath North Amer- 

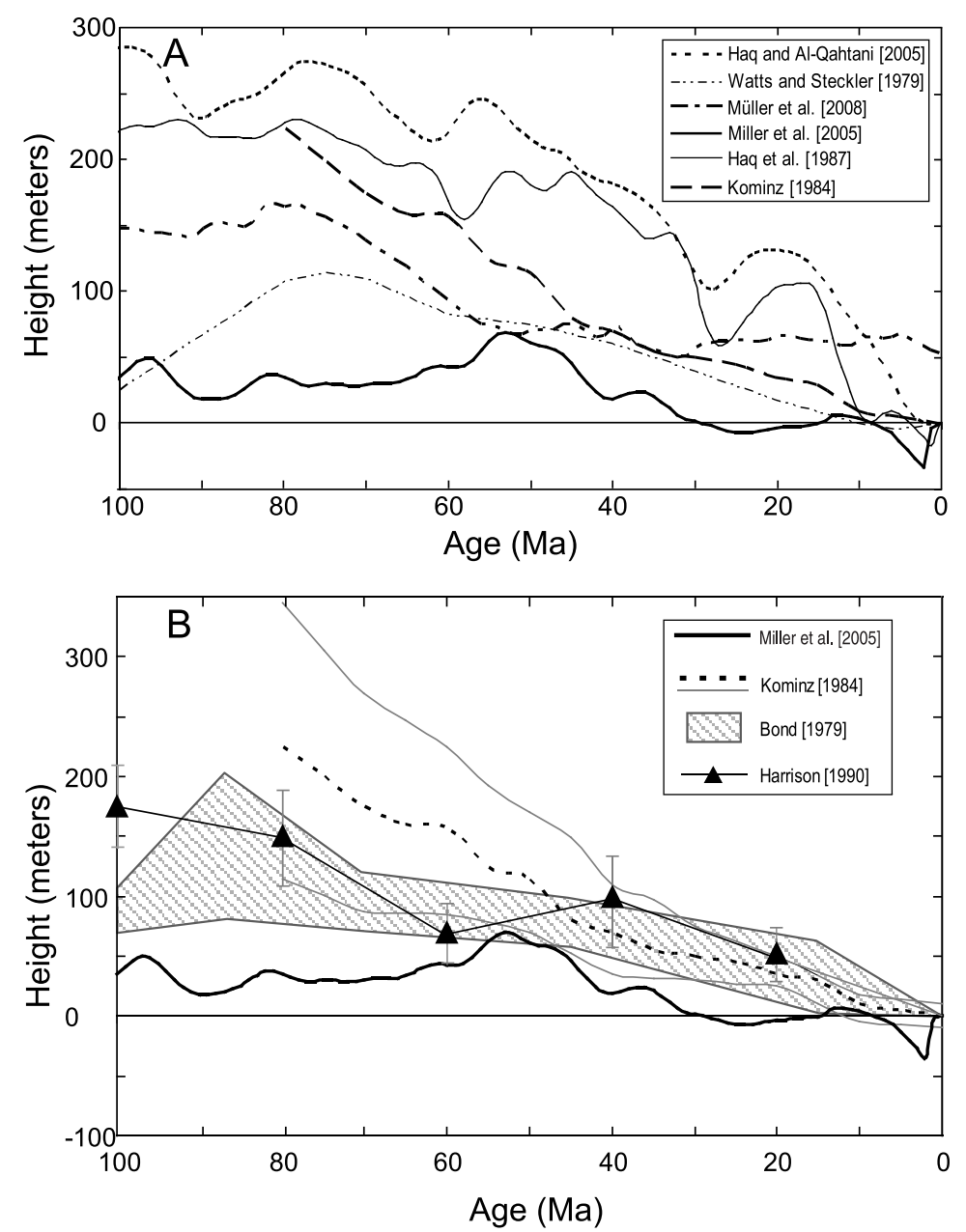

Figure 1. Comparison between sea-level curves. (a) Comparison between Haq et al. [1987], Haq and Al-Qahtani [2005], Müller et al. [2008], Kominz [1984], and Watts and Steckler [1979] curves with sea-level curve derived for New Jersey coastal plain [Miller et al., 2005] for last 100 million years, smoothed by a 10 m.y. cosine arch filter to isolate long-term sea-level change. (b) Comparison between sea-level estimates based on the analysis of continental flooding [Harrison, 1990; Bond, 1979] and Miller et al. [2005] and Kominz [1984] sea-level curves. Thin continuous lines indicate maximum and minimum estimates from Kominz [1984], hatched area shows range of estimates from Bond [1979], and black line with triangles indicate average estimates of Harrison [1990] with associated error bars.

ica using adjoint models with tomographic, plate motion and stratigraphic constraints, manuscript in preparation, 2008) that assimilate plate motions and seismic tomography to determine if reasonable dynamic models can predict the requisite dynamic subsidence. These complimentary approaches suggest that the Atlantic coastal region of the United States has been experiencing dynamic subsidence since at least the Eocene.

\section{Paleoshoreline Analysis}

[6] We analyze elevation of the paleoshoreline with respect to predictions from global sea level to infer vertical motions. If a reconstructed paleoshoreline is topographically lower (higher) than global sea level at the same time, then we can infer relative subsidence (uplift) of the region since that time. We reconstruct Miocene and Eocene shorelines using abundant marine (Paleobiology database, available at http://www.paleodb.org; the data were downloaded from the Paleobiology Database in November 2007 using the following parameters: time intervals $=$ Miocene and Eocene, region $=$ United States, paleoenvironment $=$ marine) and less preserved non-marine sediments [Tedford and Hunter, 1984; Wright and Eshelman, 1987; Gazin, 1953] along the U.S. Atlantic coast (Figures $2 \mathrm{a}$ and $2 \mathrm{~b}$ ). Paleoshorelines for the Eocene (Figure 2a) and Miocene (Figure 2b) are defined as the furthermost inland location of the marine sediments, positioned just oceanward from the non-marine location, with the exception of the youngest nonmarine sediments in North Carolina (Figure 2b), which we did not take into account since it captures the lowest Miocene sea level.

[7] Considering significant disagreement regarding inferred global sea levels described earlier, we will perform our analysis with sea levels defined by Bond [1979], Kominz [1984] and Haq and Al-Qahtani [2005] in order to define a range of possible vertical motions. The singular Eocene and Miocene levels reconstructed based on the flooding of the continents [Bond, 1979] are most probably eustatic, as discussed earlier. They are generally consistent 

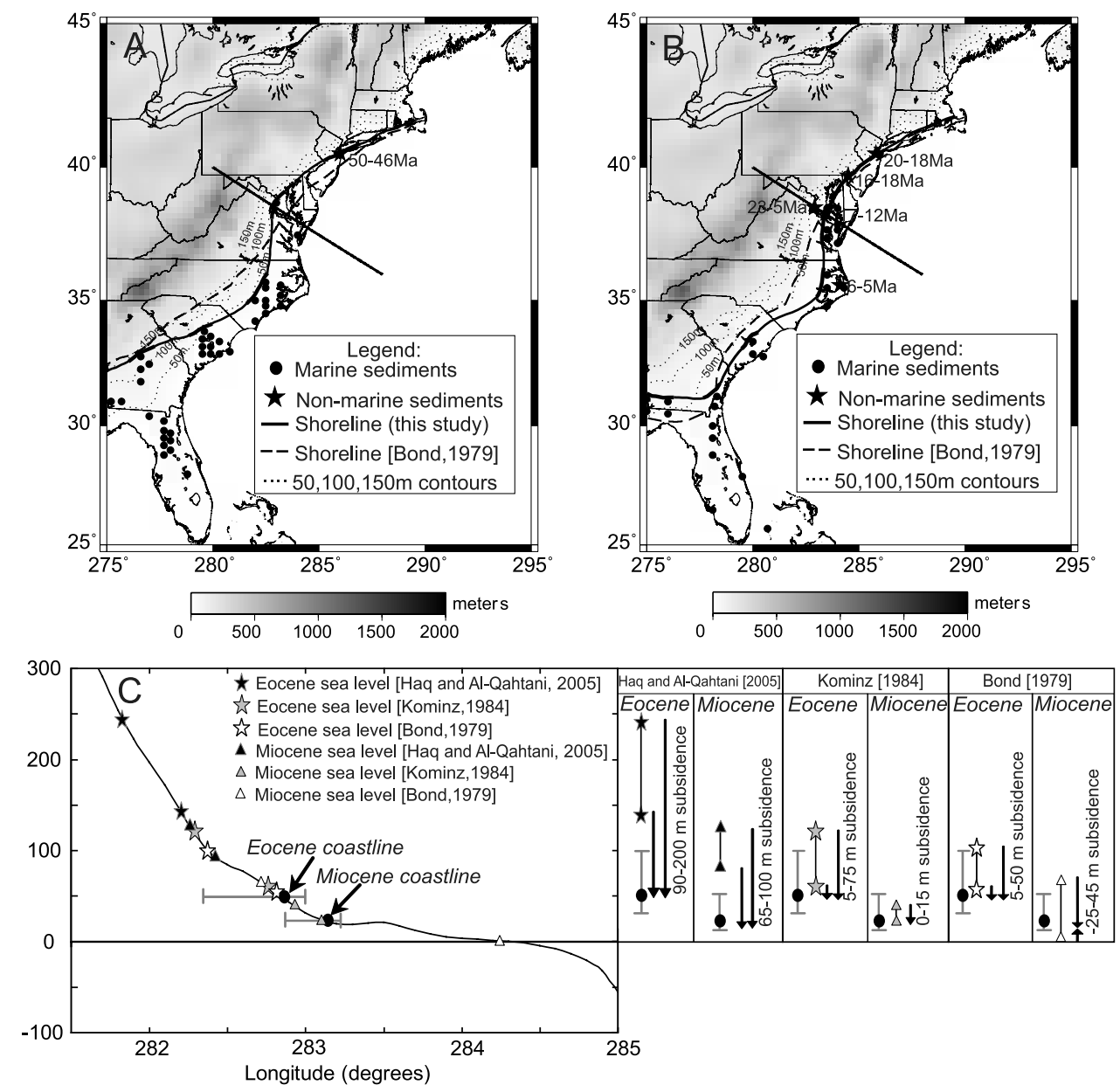

Figure 2. Paleoshoreline and hypsometric analysis of the U.S. east coast. (a) Eocene paleoshoreline reconstructions, (b) Miocene paleoshoreline reconstructions, (c) topographic profile through Chesapeake Bay (shown with a straight line on Figures 2a and 2b). Dots and stars on Figures $2 \mathrm{a}$ and $2 \mathrm{~b}$ indicate locations of marine (Paleobiology database, 2007) and non-marine [Tedford and Hunter, 1984; Wright and Eshelman, 1987; Gazin, 1953] sediments, respectively, with ages of the non-marine sediments indicated. Continuous thick lines show position of reconstructed paleoshorelines, and dashed lines indicate paleoshorelines from Bond [1979]. Dotted lines correspond to $50 \mathrm{~m}, 100 \mathrm{~m}$, and $150 \mathrm{~m}$ topographic contours. Stars and triangles on Figure 2c indicate maximum and minimum sea levels for Eocene and Miocene (18-12 Ma), respectively. Dots on the profile show positions of reconstructed shorelines in this study. Figure 2c (right) shows summary of the analysis results, with grey bars indicating qualitatively estimated uncertainty in shoreline reconstruction.

with the predicted sea level of Kominz [1984], which will also be used in the analysis since it is continuously defined for the Cenozoic. We also perform analysis using the Haq and Al-Qahtani [2005] sea level to define upper bounds on the subsidence values utilizing paleoshorelines.

[8] The elevation of the reconstructed Eocene shoreline along a northwest-southeast topographic profile through the Chesapeake Bay region is approximately $50 \mathrm{~m}$, which is lower than Eocene sea levels (Figure 2c). The estimated subsidence varies between 5-50 m (compared with Bond [1979]), 5-75 m [Kominz, 1984] and 90-200 m [Haq and Al-Qahtani, 2005]. However, the Eocene shoreline defined by Bond [1979] is $20-30 \mathrm{~m}$ topographically lower along the profile (Figure 2a) than the one we reconstructed, suggesting a higher amount of subsidence. The elevation of the Miocene paleoshoreline, with an age constrained to $18-$ $12 \mathrm{Ma}$ along the profile, is about $20 \mathrm{~m}$ (Figure 2c), suggesting up to 100 meters of subsidence since the mid Miocene (compared to Haq and Al-Qahtani [2005]). The paleoshoreline analysis is limited by the accuracy in estimating the position of paleoshorelines. In an attempt to account for limited sediment preservation, resulting in oceanward biases in estimates of paleoshoreline locations, we also include a qualitative estimate of the elevation errors (Figure 2c). Our subsidence estimate since $12 \mathrm{Ma}$ based on a comparison with Kominz [1984] and Bond [1979] sea levels are small, only several 10's of meters, and within their error estimates. However, the estimated subsidences for the Eocene are outside of the error estimates.

[9] In summary, although the paleoshorelines analysis is characterized by relatively large uncertainty, the trends from the paleoshorelines indicate at least $50 \mathrm{~m}$, and possibly as much as $200 \mathrm{~m}$ of subsidence since the Eocene. The subsidence since the late Miocene is probably relatively 
small, and it is hard to constrain using the paleoshoreline analysis alone.

\section{Mantle Convection Model: The Changing Cenozoic Dynamic Topography in the Eastern United States}

[10] As mantle buoyancy forces rearrange, dynamic topography changes; as plates move with respect to these changes, sea level undergoes global fluctuations while continental interiors experience epeirogenic motions
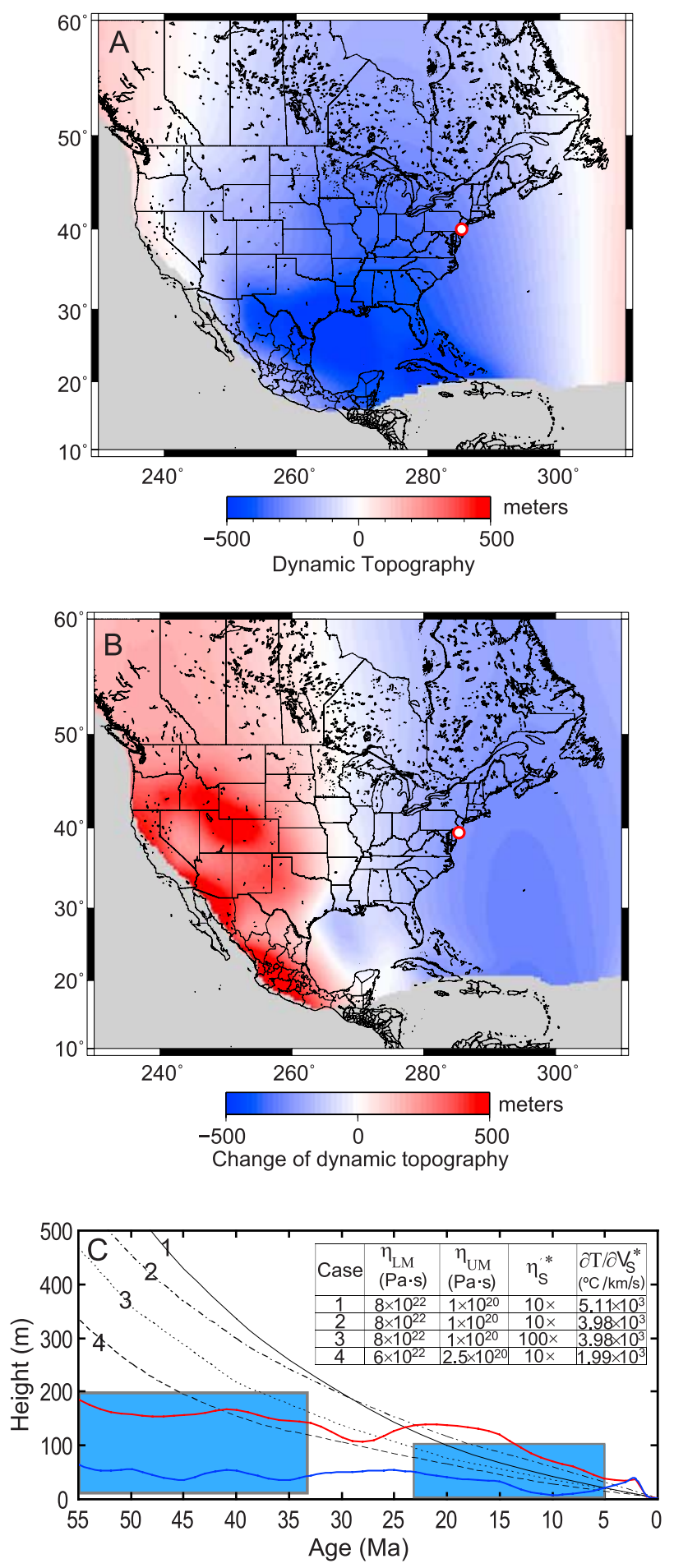

[Gurnis, 1992]. Using a global flow model, LithgowBertelloni and Gurnis [1997] showed that as North America moved westward since the Cretaceous, the western interior subsided and then uplifted. Ever since the Mitrovica et al. [1989] model predicting Cretaceous subsidence and Tertiary uplift, it has been generally thought that the western interior seaway subsidence was driven by dynamic topography [e.g., Liu and Nummedal, 2004]. However, up to this point no detailed estimates of dynamic motions have been made for the eastern region of the continent. As North America moved to the west, is it possible that the Cretaceous subsidence and subsequent uplift of the western interior and the putative subsidence of the eastern United States can both be predicted with a single geodynamic model?

[11] This question is addressed with three-dimensional regional spherical finite element models for North America with temperature- and pressure-dependant viscosity, and imposed plate kinematics using the software package CitcomS [Tan et al., 2006]. When comparing predicted and inferred paleoshorelines and dynamic topography with borehole tectonic subsidence curves, it is essential that the topography on a mesh fixed to the plate be continuously tracked over the changing mantle [Gurnis et al., 1998]. An inverse methodology is used to solve mantle convection (L. Liu and M. Gurnis, Simultaneous inversion of mantle viscosity and initial conditions from an adjoint of mantle convection, submitted to Journal of Geophysical Research, 2008), where past mantle structure is recovered through backward integration of the convection equations using the scaled seismic tomography of Grand [2002]. The regional North American model was developed for the period from $100 \mathrm{Ma}$ to present, and is constrained by observations of flooding, sediment thickness and tectonic subsidence, mainly in the Cretaceous interior seaway (see Liu

Figure 3. Dynamic topography predictions from the North America mantle convection models. (a) Predicted presentday dynamic topography, (b) difference between predicted dynamic topography for early Eocene $(50 \mathrm{Ma})$ and presentday $(0 \mathrm{Ma}),(\mathrm{c})$ dynamic topography subsidence for a well in New Jersey coastal plain (location is shown with a white circle on Figures $3 \mathrm{a}$ and $3 \mathrm{~b}$ ). The model shown in Figures $3 \mathrm{a}$ and $3 \mathrm{~b}$ is Case 4, with the parameters given in Figure 3c. Dynamic topography change for a well in New Jersey coastal plain (coordinates $285^{\circ} 30^{\prime}, 39^{\circ} 30^{\prime} \mathrm{N}$ ) for four dynamic models is shown with black lines, solid red and blue lines show difference between sea-level models of $\mathrm{Haq}$ and Al-Qahtani [2005] and Miller et al. [2005], and Kominz [1984] and Miller et al. [2005], respectively. Blue colored boxes show estimated subsidence range from paleoshoreline analysis for Eocene and Miocene. Table insert shows model parameters $(\eta=$ viscosity, $L M=$ lower mantle, $U M=$ upper mantle viscosity, $\eta_{S}^{\prime}=$ non-dimensional variation in viscosity across the slab compared to ambient values at the same depth, $T=$ temperature, $V_{s}=$ shear wave velocity, * = values are evaluated at $2000 \mathrm{~km}$ depth). Dynamic topography was calculated as if were an interface between mantle and water. 
et al. (manuscript in preparation, 2008) for a complete discussion).

[12] Dynamic models predict a broad present-day dynamic topography low over the eastern portion of the United States (Figure 3a). Since the early Eocene, total subsidence due to the change of dynamic topography is on order of $500 \mathrm{~m}$ (Figure 3b), but it varies from $350 \mathrm{~m}$ to $700 \mathrm{~m}$, depending on the rheological parameters and the seismic wave speed to temperature scaling (Figure 3c). The predicted uplift in the interior of the United States is on order of $500 \mathrm{~m}$ (Figure 3b) to $1 \mathrm{~km}$, depending on model parameters. Although a suite of models were run (Liu et al., manuscript in preparation, 2008), as illustrated by four models in Figure $3 \mathrm{c}$, a model that predicts that the U.S. east coast is either stable or uplifting was never found. Dynamic predictions of subsidence (Figure 3c) since the late Miocene are around $50 \mathrm{~m}$, which is consistent with an intermediate estimate from the paleoshoreline analysis using the Haq and Al-Qahtani [2005] sea level, and with a high-end estimate using the Bond [1979] sea level. On the hand, the range of estimated dynamic subsidence since the end of the Eocene is 120-225 m (Figure 3c), which is higher than estimates from paleoshoreline analysis using the Bond [1979] and Kominz [1984] sea levels, and consistent with estimates based on the Haq and Al-Qahtani [2005] sea-level curve. If the subsidence occurred in the earlier parts of the Eocene, dynamic models (Liu et al., manuscript in preparation, 2008) overpredict the magnitude of subsidence (Figure 3c). Discrepancies between the Miller et al. [2005] sea level and other analyzed curves (Figure 3c) are also consistent with the proposed subsidence. Although all analyzed data are consistent with an overall subsidence since the Eocene (Figure 3c), its magnitude and timing are not well constrained due to the uncertainties in all of the applied methodologies.

\section{Conclusions}

[13] Analysis of paleoshorelines and dynamic models are mutually consistent and provide evidence for dynamic subsidence of the Atlantic coast of the United States over the Cenozoic. The paleoshorelines analysis is characterized by relatively large uncertainty related to errors in defining the paleoshoreline position and different global sea-level curves that can be used. However, the trends from the paleoshorelines indicate at least $50 \mathrm{~m}$, and possibly as much as $200 \mathrm{~m}$, of subsidence since the Eocene, if the sea level defined by Haq and Al-Qahtani [2005] is used in the analysis. The subsidence since the late Miocene is probably relatively small, and it is hard to constrain using the paleoshoreline analysis alone. Adjoint mantle convection models constrained by globally consistent plate motions, present-day tomographic structure and stratigraphic observations (Liu et al., manuscript in preparation, 2008), never predict stability or uplift on the east coast of the United States since the Eocene. Dynamic models rather predict a broad dynamic topography depression that produces dynamic topography subsidence of 350-700 $\mathrm{m}$ over the Cenozoic, and 125-225 $\mathrm{m}$ since the end of Eocene. Although the exact amplitude and timing of the Cenozoic subsidence is difficult to constrain, dynamic models and paleoshoreline analysis seem to be consistent with subsi- dence of at least $50 \mathrm{~m}$, and possibly as large as $200 \mathrm{~m}$, since the Eocene.

[14] The dynamic subsidence in the U.S. east coast is explained in an integrated mantle convection model, which also predicts Cretaceous subsidence and subsequent uplift in the western interior (Liu et al., manuscript in preparation, 2008). The widespread flooding of the North American interior is caused by coincident maximum global sea level in the Cretaceous and motion of the interior of the continent over a broad dynamic topography low. Since the Eocene, the dynamic subsidence of the U.S. east coast occurred simultaneously with a lowering of the global sea level, with the eustatic fall being larger than dynamic subsidence. This results in a dynamic subsidence that cannot be as easily recognized in the stratigraphic record, compared to the western interior flooding during the Cretaceous. The discrepancy between the sea-level fall for the last $100 \mathrm{Ma}$ derived for New Jersey coastal plain wells [Miller et al., 2005] and global sea-level curves [Bond, 1979; Kominz, 1984; Haq and Al-Qahtani, 2005] is consistent with the proposed dynamic subsidence. We propose that this discrepancy can be eliminated if vertical movements of the North American continent due to dynamic topography are taken into account.

[15] Acknowledgments. We thank Michelle Kominz and Ken Miller for helpful reviews. The CitcomS software was obtained from CIG (http:/ geodynamics.org). This is Contribution 8996 of the Division of Geological and Planetary Sciences and 87 of the Tectonics Observatory. Supported in part of NSF grant EAR-0609707 and by the Gordon and Betty Moore Foundation through the Caltech Tectonics Observatory.

\section{References}

Bond, G. (1979), Evidence for some uplifts of large magnitude in continental platforms, Tectonophysics, 61, 285-305.

Bunge, H.-P., and S. P. Grand (2000), Mesozoic plate-motion history below the northeast Pacific Ocean from seismic images of the subducted Farallon slab, Nature, 405, 337-340.

Gazin, C. L. (1953), The Tillodontia: An early Tertiary order of mammals, Smithson. Misc. Collect., 121(10), 1-110.

Grand, S. P. (2002), Mantle shear-wave tomography and the fate of subducted slabs, Philos. Trans. R. Soc. London, Ser. A, 360, 2475-2491.

Gurnis, M. (1992), Long-term controls on eustatic and epeirogenic motions by mantle convection, GSA Today, 2, 141-157.

Gurnis, M., R. D. Müller, and L. Moresi (1998), Cretaceous vertical motion of Australia and the Australian-Antarctic Discordance, Science, 279 $1499-1504$

Hager, B. H., C. W. Clayton, M. A. Richards, R. P. Comer, and A. D. Dziewonski (1985), Lower mantle heterogeneity, dynamic topography and the geoid, Nature, 313(6003), 541-545.

Harrison, C. G. A. (1990), Long-term eustasy and epeirogeny in continents, in Sea-Level Change, edited by R. Revelle, pp. 141-160, Natl. Acad. Press, Washington, D.C.

Haq, B. U., and A. M. Al-Qahtani (2005), Phanerozoic cycles of sea-level change on the Arabian Platform, GeoArabia, 10(2), 127-160.

Haq, B. U., J. Hardenbol, and P. R. Vail (1987), Chronology of fluctuating sea levels since the Triassic, Science, 235, 1156-1167.

Kominz, M. A. (1984), Oceanic ridge volumes and sea level change: an error analysis, in Interregional Unconformities and Hydrocarbon Accumulation, edited by J. Schlee), AAPG Mem., 36, 109-127.

Lithgow-Bertelloni, C., and M. Gurnis (1997), Cenozoic subsidence and uplift of continents from time-varying dynamic topography, Geology, 25, $735-738$.

Lithgow-Bertelloni, C., and M. A. Richards (1998), The dynamics of Cenozoic and Mesozoic plate motions, Rev. Geophys., 36, 27-78.

Liu, S., and D. Nummedal (2004), Late Cretaceous subsidence in Wyoming: Quantifying the dynamic component, Geology, 32, 397-400.

Miller, K. G., M. A. Kominz, J. V. Browning, J. D. Wright, G. S. Mountain, M. E. Katz, P. J. Sugarman, B. S. Cramer, N. Christie-Blick, and S. F. Pekar (2005), The Phanerozoic record of global sea-level change, Science, 310, 1293-1298. 
Mitrovica, J. X., C. Beaumont, and G. T. Jarvis (1989), Tilting of continental interiors by the dynamical effects of subduction, Tectonics, 8 , 1079-1094.

Müller, R. D., M. Sdrolias, C. Gaina, B. Steinberger, and C. Heine (2008), Long-term sea-level fluctuations driven by ocean basin dynamics, Science, 319, 1357-1362.

Ren, Y., E. Stutzmann, R. D. van der Hilst, and J. Besse (2007), Understanding seismic heterogeneities in the lower mantle beneath the Americas from seismic tomography and plate tectonic history, J. Geophys. Res., 112, B01302, doi:10.1029/2005JB004154.

Richards, M. A., and B. H. Hager (1984), Geoid anomalies in a dynamic Earth, J. Geophys. Res., 89, 5987-6002.

Ritsema, J., and H. J. van Heijst (2000), Seismic imaging of structural heterogeneity in Earth's mantle: Evidence for large-scale mantle flow, Sci. Progress, 83, 243-259.

Steinberger, B. (2007), Effects of latent heat release at phase boundaries on flow in the Earth's mantle, phase boundary topography and dynamic topography at the Earth's surface, Phys. Earth Planet. Inter., 164, 2 20, doi:10.1016/j.pepi.2007.04.021

Tan, E., E. Choi, P. Thoutireddy, M. Gurnis, and M. Aivazis (2006), GeoFramework: Coupling multiple models of mantle convection within a computational framework, Geochem. Geophys. Geosyst., 7, Q06001, doi:10.1029/2005GC001155.
Tedford, R. H., and M. E. Hunter (1984), Miocene marine-nonmarine correlations, Atlantic and Gulf Coastal Plains, North America, Palaeogr. Palaeoclimatol. Palaeoecol., 47, 129-151.

Van Sickel, W. A., M. Kominz, K. G. Miller, and J. V. Browning (2004), Late Cretaceous and Cenozoic sea-level estimates: backstripping analysis of borehole data, onshore New Jersey, Basin Res., 16, 451-465.

Watts, A. B., and M. S. Steckler (1979). Subsidence and eustasy at the continental margin of eastern North America, in Deep Drilling Results in the Atlantic Ocean: Continental Margins and Paleoenvironment, Maurice Ewing Ser., vol. 3, edited by M. Talwani, W. Hay, and W. B. F. Ryan, pp. 218-234, AGU, Washington, D.C.

Wright, D. B., and R. E. Eshelman (1987), Miocene Tayassuidae (Mammalia) from the Chesapeake Group of the Mid-Atlantic coast and their bearing on marine-nonmarine correlation, J. Paleontol., 61(3), 604-618.

M. Gurnis, L. Liu, and S. Spasojević, Seismological Laboratory, California Institute of Technology, Pasadena, CA 91125, USA. (sonja@ gps.caltech.edu)

R. D. Müller, School of Geosciences, University of Sydney, Sydney, NSW 2006, Australia. 